\title{
Construction project planning under fuzzy time constraint
}

\author{
N. Ibadov ${ }^{1}$ \\ Received: 15 December 2017 / Revised: 27 March 2018 / Accepted: 7 May 2018 / Published online: 22 May 2018 \\ (c) The Author(s) 2018
}

\begin{abstract}
A distinctive feature of construction projects is the uniqueness of conditions for their implementation. Therefore, the durations data of the works are often formulated imprecisely. On the other hand, the time limit for the execution of the works is defined in the contract conditions by data indicating the due time and the deadline. These indicate the distribution of time values, which the contractor can allocate for the implementation of the construction project in accordance with the client preferences. For assessing the compliance of the planned project makespan with the fuzzy time constraint, it is recommended to use the fuzzy sets theory. The article presents a method for assessing the level of satisfaction of fuzzy constraint of time for the execution of construction works using the probabilistic measure, in conjunction with the concept of $\alpha$-cuts of a fuzzy number. The application of the presented method is demonstrated on a numerical example, which shows the compliance of the evaluation results with those obtained with the simulation methods. The article confirms the correctness of the assumptions of the presented method, which allows for its use for the formulation and resolving schedule optimization problems in the case of imprecisely formulated schedule input data.
\end{abstract}

Keywords Construction planning $\cdot$ Fuzzy constraints $\cdot$ Fuzzy scheduling $\cdot$ Probabilistic measure

\section{Introduction}

In planned construction projects, there is always a necessity to foresee possible completion dates of project in relation to deadline imposed by a client. To fulfill this requirement, it is required to take under consideration various delaying factors (Ibadov 2016a, b, 2017). Calculated durations under influence of those factors are then compared with constraints deriving from the project agreement. Therefore, predicting possibility of fulfilling required completion dates is of key importance for planning construction projects. In the literature, there are various methods and techniques for calculating duration of construction projects. Chosen methods and techniques for assessing construction works duration are presented by Juszczyk (2014) and Rosłon (2017). Despite many tools supporting construction management, delays keep occurring in construction projects (Głuszak and

Editorial responsibility: Dr. Iskender Akkurt.

N. Ibadov

n.ibadov@il.pw.edu.pl

1 The Faculty of Civil Engineering, Warsaw University of Technology, Warsaw, Poland
Leśniak 2015). Therefore, there is a constant need for finding relevant methods of defining projects duration underset constraints. It is worth stressing that a distinctive feature of construction projects is the uniqueness of conditions for their implementation. Therefore, the data on durations of the works are often formulated imprecisely, for example, "about 3 weeks," "2 to 3 weeks," and the like. To model ill-defined durations of the works, fuzzy numbers are used (Kulejewski 2010a, 2011; Lorterapong and Moselhi 1996). On the other hand, the time limit for the execution of the works is defined in the contract conditions by data indicating the due time and the deadline. These indicate the distribution of time values, which the contractor can allocate for the implementation of the construction project in accordance with the client preferences. For assessing the compliance of the planned project makespan with the fuzzy time constraint, it is recommended to use the theory of fuzzy sets (Dubois et al. 2003). However, the result of this assessment significantly depends on the optimism or pessimism of the planner. This article demonstrates that for the neutralization of assessing the level of meeting the fuzzy time constraint, a probabilistic measure can be used, in conjunction with the concept of $\alpha$-cuts of a fuzzy number. The research was done in Warsaw (Poland) in year 2017. 


\section{Materials and methods}

From the methodological point of view, the article concerns uncertainty modeling in planning and scheduling of construction projects (with time constraints), with the use of mathematical tools-fuzzy set theory and probabilistic measure.

In construction industry, during project planning phase one has to take into consideration the occurrence of unfavorable events and its consequences (characterized by term "risk"). In the scientific literature, it is often underlined that risk factors are random and can be described with the use of probability theory (in contrast to "uncertainty," which cannot be described in a quantitative way). Such approach requires the knowledge on probability distribution of these factors. However, in construction practice it is impossible to assume probability distribution for a hypothetical event. That is why, all risk factors for a construction project are subject to uncertainty. Due to this fact, the construction manager (decision maker) should know that using any probability distribution hypothesis for random variables may result in incompatibility of the results with actual conditions. In majority of cases, decision is made while goals, constraints and consequences of events (or actions) are not clear. That is why, the use of probabilistic methods for planning and scheduling is well justified when one knows the probability of possible disruptions which may lead to specific results. Due to the lack of such possibility, people responsible for creation of construction schedules use heuristic knowledge gathered thanks to identification of facts and finding dependencies between them. The rationale and conclusions of the above hypotheses are formulated imprecisely, often with the use of concepts specific to colloquial language. For example, the occurrence of a selected factor with a given severity results in extension of the given work by about 5 days or seven to eight working days.

Mathematical basis of the fuzzy sets theory allows using imprecisely determined relationships between the frequency and intensity of a given disturbance, and its effects, to determine fuzzy numbers showing the distribution of possible times of performing individual works.

The existence of such a possibility (in light of the imperfection of the probabilistic methods of scheduling) has become the reason for the development of network model analysis methods with fuzzy durations of activities, and fuzzy scheduling and project planning methods. Numerous articles are devoted to this topic, and various authors try to model the uncertainty using fuzzy set theory separately or together with other mathematical tools. Worth mentioning is the work of Afsordegan et al. (2016) which takes into account linguistic data provided by the decision makers without any previous aggregation. Li et al. (2015) suggest an interval fuzzy-robust two-stage stochastic-robust programming model for management in conditions of uncertainty. The model can enhance the robustness for the optimization process under fuzzy constraints. Some adjustments for decision making in conditions of uncertainty were made by Xu et al. (2012) by creation of a compromise optimization model, in which total duration of the project is considered to be a fuzzy variable. In this model a fuzzy-based adaptive-hybrid genetic algorithm is developed to find feasible solutions for time-cost-environment trade-off problem for largescale construction projects. For various levels of project planning, Masmoudi and Haït (2013) developed a solving procedure by considering a fuzzy modeling of the workload inspired from the fuzzy/possibilistic approach. Plebankiewicz and Karcińska (2016) suggested scheduling methods basing on fuzzy values of working time norms and employee numbers. The proposed procedure allows for determining a real duration of a project taking into account various factors affecting durations of single activities. Castro-Lacouture et al. (2009) analyzed the implementation of fuzzy sets in schedule planning when time, costs and resources were limited. Each of the above-mentioned models supports decision making in the applied field.

Analysis of current scheduling methods that include uncertainty (probabilistic methods, fuzzy sets theory methods) can lead to the following assumption. Due to the uniqueness of construction contract conditions, even for the most advanced predictive-reactive scheduling methods with use of probability (Herroelen and Leus 2005), subjective data should be used based on activity duration probability distribution. However, expert knowledge is rough and hypothesis related to entered data for scheduling is not explicit, very often with use of verbal definitions. Theory of fuzzy sets allows for modeling and processing of data which is difficult to be quantified by use of probabilistic or statistical methods. According to Kulejewski (2010b), existing methods of schedule creation with fuzzy sets which are presented in articles by Chanas and Zieliński (2001, 2002), Hapke and Słowiński (1996, 2000), Lorterapong and Moselhi (1996), Wang (1999, 2002, 2004), Slyeptsov and Tyshchuk (2003) do not provide satisfying results related to:

- calculations of latest completion times and identification of critical activities and paths in fuzzy model of construction networks,

- assessment of time-constrained compliance level in case when activities completion time is not precisely set,

- transformation of fuzzy schedule to regular schedule with assurance of a level for imprecisely set constraints of completion time. 
Taking the above under the consideration, there is a need to develop such methods of scheduling which will include fuzzy modeling of imprecise planning data and which assure the requested level of completion time constraint which is set in an imprecise way.

\section{Basic concepts of fuzzy sets theory and uncertainty modeling}

The following information includes only a part of fuzzy sets theory, which is directly connected to this article. The area considered in the fuzzy sets theory is a certain non-empty space $X$, which is a non-fuzzy set. In this space, a certain set $A$ is fuzzy if elements $x \in X$ belong that set with some grade of membership $\mu$ (Rutkowski 2006). A fuzzy number is a fuzzy set $A \subseteq R$, whose membership function $\mu_{A}(x)$ is at least segmentally continuous, and fuzzy set $A$ is convex and normalized. The sum and maximum of two fuzzy numbers $\tilde{A}=\left(a_{1}, a_{2}, a_{3}, a_{4}\right)$ and $\tilde{B}=\left(b_{1}, b_{2}, b_{3}, b_{4}\right)$ can be calculated using the following equations (Dubois and Prade 1978):

$\tilde{A} \oplus \tilde{B}=\left(a_{1}+b_{1}, \ldots, a_{4}+b_{4}\right)$

$\max \{\tilde{A}, \tilde{B}\}=\left(\max \left\{a_{1}, b_{1}\right\}, \ldots, \max \left\{a_{4}, b_{4}\right\}\right)$

In turn, $\alpha$-cuts of a fuzzy set $A \subseteq X$ are such non-fuzzy set $A^{\alpha}$ (Rutkowski 2006):

$A^{\alpha}=\left\{x \in X: \mu_{A}(x) \geq \alpha\right\}, \quad \forall_{\alpha \in[0,1]}$

Each non-fuzzy set $A^{\alpha}$ can be presented in the interval notation $\left[a_{\mathrm{L}}^{\alpha}, a_{\mathrm{U}}^{\alpha}\right]$ in the following manner:

$a_{L}^{\alpha}=\inf _{x \in R}\left(A^{\alpha}\right), a_{U}^{\alpha}=\sup _{x \in R}\left(A^{\alpha}\right)$

To compare fuzzy numbers, one can use terms like degree of necessity $N(Z)$ and degree of possibility $\Pi(Z)$ for occurrence of a specified event $Z$ (Dubois and Prade 1992). Relations between degrees of necessity and possibility are as follows:

$$
\begin{aligned}
& N(Z)=\inf _{x \notin Z}\left(1-\mu_{Z}(x)\right)=1-\Pi(\neg Z) \\
& \Pi(Z)=\sup _{x \in Z}\left(\mu_{Z}(x)\right)=1-N(\neg Z)
\end{aligned}
$$

where $(\neg Z)$ is an event opposite to event $Z, \mu_{Z}(x)$ is a membership function $Z$.

\section{Basic concepts of fuzzy network modeling analysis}

In the fuzzy network, modeling analysis durations of single activities are fuzzy numbers. Figure 1 shows an example of modeling activity duration as trapezoidal number.

Fuzzy critical path method (FCPM) is used for most projects. The principles of this method are like the conventional

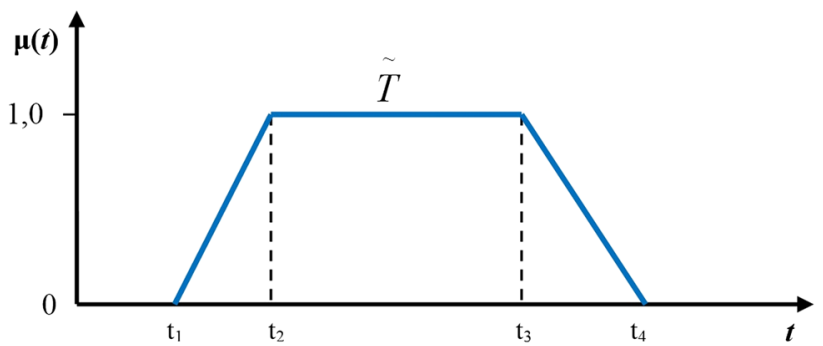

Fig. 1 An example of using a trapezoidal fuzzy number for activity duration modeling

critical path method (CPM) (Soltani and Haji 2007). The length of the longest network path (in terms of duration) is a so-called critical path of the project. It is important to note that there are many flaws of determining a critical path. Many articles were devoted to this subject. In order to determine critical path with fuzzy activities' durations, authors use various methods of ranking fuzzy numbers (Elizabet and Sujatha 2013; Chandra and Kumar 2014; Shankar et al. 2010a, b). The described methods have some flaws. First of all, in a case that there are multiple critical paths there is a problem in selecting one of the alternative critical durations. Furthermore, in previously proposed algorithms an activity can have different durations if it is located on several paths, which is a major flow of solution. Moreover, there are some problems in determining slack.

It seems that the key aspect of fuzzy project planning is calculating finish time of the whole project. In this regard, Huang, Oh and Pedrycz (2013) propose three fuzzy programming models for estimating the overall completion time of project. The proposed models are handled through techniques that combine mechanisms of fuzzy simulation and genetic optimization. In this setting, fuzzy simulation is exploited to estimate the value of uncertain functions. Khalilzadeh et al. (2017) develop an algorithm for project scheduling with fuzzy time and resources. This algorithm first calculates the latest start times of activities under fuzzy environment and then constructs a feasible schedule by using the parallel scheduling method. Taking into consideration above-mentioned flaws, the author of this article is sticking only to the basic formulas and concepts useful for solving the network models presented later in this article.

While modeling a course of the project using a singlepoint fuzzy network with finish-to-start dependencies between activities, earliest starting times and finish times of individual activities can be determined based on the dependencies similar to those used in the classic CPM method (Chanas and Kamburowski (1981):

$\widetilde{E S}_{j}=\max _{i \in \operatorname{Prec}\{(j)\}}\left\{\widetilde{E S}_{j} \oplus \tilde{D}_{i}\right\}$ 
$\widetilde{E F_{j}}=\widetilde{E S_{j}} \oplus D_{j}, \quad j=1, \ldots, J$

where $\widetilde{E S}_{j}$-fuzzy early start time for activity j, $\operatorname{Prec}\{(j)\}$-set of $\mathrm{j}$ activity predecessors, $\widetilde{E F_{j}}$-fuzzy early finish time for activity j, $D_{j}$-fuzzy duration of activity $\mathrm{j}$.

Adding fuzzy numbers can be done according to Eq. (1). The maximum of fuzzy numbers is determined using Eq. (2).

Fuzzy duration of a project can be calculated in the following manner (Lorterapong and Moselhi 1996):

$\tilde{T}=\widetilde{E F}$

\section{Assessing the compliance with the fuzzy time constraint}

According to Dubois et al. (2003) and Zadeh (1999), to assess the compliance with the fuzzy time constraint one should estimate the degree of necessity and the degree of possibility of the relationship $\tilde{T} \leq \tilde{T}_{D}$, where fuzzy number $\tilde{T}$ models the estimated construction project makespan and fuzzy number $\tilde{T}_{D}$ models the fuzzy time constraint. The shapes of these fuzzy numbers are shown in Fig. 2.

It should be noticed that the assessment of the possibility degree of the relation $\tilde{T} \leq \tilde{T}_{D}$ is not complementary to the assessment of the degree of occurrence of the opposite relation. This means that $\Pi\left(\tilde{T} \leq \tilde{T}_{D}\right)$ need not be equal to $1-\Pi\left(\tilde{T} \geq \tilde{T}_{D}\right)$. For this reason, there is a search in the literature for a synthetic indicator, having (in line with the intuition of the planner) the property of complementarity. Such a property characterizes a schedule performance measure, introduced by Wang (2002) as the schedule risk:

$\mathrm{SR}=\beta \Pi\left(\tilde{T}>\tilde{T}_{\mathrm{D}}\right)+(1-\beta) N\left(\tilde{T}>\tilde{T}_{\mathrm{D}}\right)$

where $\beta$ is a coefficient, characterizing the level of optimism. It should be noticed that using Eq. (10), the planners at different levels of optimism are not unanimous in their assessment of the level to meet the fuzzy constraint on the construction project makespan.

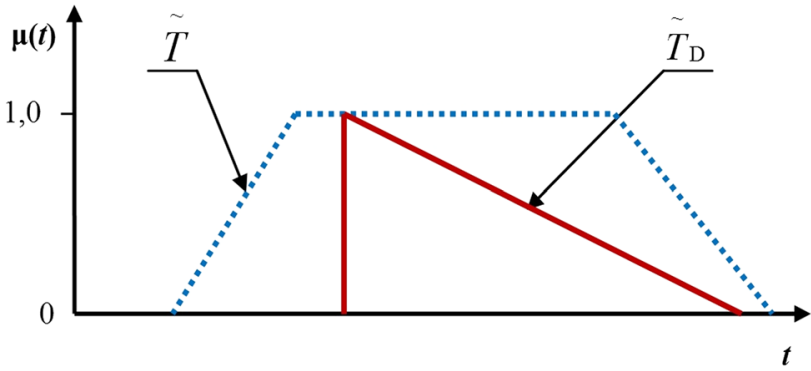

Fig. 2 Fuzzy numbers $\tilde{T}$ and $\tilde{T}_{\mathrm{D}}$

\section{Probabilistic assessment of the compliance with the fuzzy time constraint}

The main idea of the described below method for compliance assessment with the fuzzy time constraint is to use the concept of $\alpha$-cuts of fuzzy numbers $\tilde{T}$ and $\tilde{T}_{\mathrm{D}}$ to designate interval numbers $T^{\alpha}$ and $T_{D}^{\alpha}$. Those interval numbers are further compared with the use of the probabilistic measure and probability $P\left(T^{\alpha}>T_{D}^{\alpha}\right)$ is calculated. By the aggregation of probability $P\left(T^{\alpha}>T_{D}^{\alpha}\right)$ calculated for the finite number of $\alpha$-cuts of fuzzy numbers $\tilde{T}$ and $\tilde{T}_{\text {D }}$, probability $P\left(\tilde{T}>\tilde{T}_{D}\right)$ is obtained. The probability that the planned construction project makespan is no longer than the project makespan preferred by the client is:

$P\left(\tilde{T} \leq \tilde{T}_{D}\right)=1-P\left(\tilde{T}>\tilde{T}_{D}\right)$

Figure 3 depicts an example of interval numbers $T^{\alpha}$ and $T_{\mathrm{D}}^{\alpha}$ designation for some $\alpha$-cut of fuzzy numbers $\tilde{T}$ and $\tilde{T}_{\mathrm{D}}$. Choosing a real number $t$ in the interval $T^{\alpha}$ and a real number $t_{\mathrm{d}}$ in the interval $T_{\mathrm{D}}^{\alpha}$, one will receive a pair of real numbers $\left(t, t_{\mathrm{d}}\right)$. Figure 3 shows that a real number $t$ may take a value from one of the subintervals $T_{(1)}^{\alpha}=\left[t_{L}^{\alpha}, t_{d_{L}}^{\alpha}\right]$, $T_{(2)}^{\alpha}=\left[t_{d_{L}}^{\alpha}, t_{d_{U}}^{\alpha}\right]$ or $T_{(3)}^{\alpha}=\left[t_{d_{U}}^{\alpha}, t_{U}^{\alpha}\right]$, whereas, a real number $t_{\mathrm{d}}$ will always take value from the subinterval $\left[t_{d_{L}}^{\alpha}, t_{d_{U}}^{\alpha}\right]$. As a result, there may be one of the events $Z_{q}$ such that $Z_{q}=\left(t \in T_{(q)}^{\alpha}, t_{d} \in T_{D}^{\alpha}\right), q=1,2,3$. The events $t \in T_{(q)}^{\alpha}$ and $t_{\mathrm{d}} \in T_{D}^{\alpha}$ are independent, because:

$P\left(Z_{q}\right)=P\left(t \in T_{(q)}^{\alpha}\right) P\left(t_{d} \in T_{D}^{\alpha}\right)$

The probability $P\left(t_{\mathrm{d}} \in T_{D}^{\alpha}\right)=1$. The probability $P\left(t \in T_{(q)}^{\alpha}\right)$ can be assessed geometrically, comparing the length of the subinterval $T_{(q)}^{\alpha}$ and the length of the subinterval $T^{\alpha}$. On this basis, one obtains:

$P\left(Z_{1}\right)=\frac{t_{d_{L}}^{\alpha}-t_{L}^{\alpha}}{t_{U}^{\alpha}-t_{L}^{\alpha}} ; \quad P\left(Z_{2}\right)=\frac{t_{d_{U}}^{\alpha}-t_{d_{L}}^{\alpha}}{t_{U}^{\alpha}-t_{L}^{\alpha}} ; \quad P\left(Z_{3}\right)=\frac{t_{d_{U}}^{\alpha}-t_{d_{L}}^{\alpha}}{t_{U}^{\alpha}-t_{L}^{\alpha}}$



Fig. 3 Example of designation of interval numbers $T^{\alpha}$ and $T_{\mathrm{D}}^{\alpha}$ 
The probability that a real number $t$ chosen from the interval $\left[t_{L}^{\alpha}, t_{U}^{\alpha}\right]$ proves to be greater than the real number $t_{\mathrm{d}}$ chosen from the interval $\left[t_{d_{L}}^{\alpha}, t_{d_{U}}^{\alpha}\right]$ is the conditional probability $P\left(T^{\alpha}>T_{D}^{\alpha} \mid Z_{q}\right)$. An event $Z_{2}$ is selected as a real number $t$ and a real number $t_{d}$ from the same subinterval $T_{(2)}^{\alpha}=\left[t_{d_{L}}^{\alpha}, t_{d_{U}}^{\alpha}\right]$. It can therefore be assumed that when the event $Z_{2}$ will occur, the probability that the chosen real number $t$ will be greater than the chosen real number $t_{\mathrm{d}}$, is $P\left(T^{\alpha}>T_{D}^{\alpha} \mid Z_{2}\right)=0,5$. In the case of occurrence of the event $Z_{1}$, a real number $t$ will be always lower than a real number $t_{\mathrm{d}}$. Therefore, $P\left(T^{\alpha}>T_{D}^{\alpha} \mid Z_{1}\right)=0$. Finally, if the event $Z_{3}$ will occur, a real number $t$ will be always greater than a real number $t_{\mathrm{d}}$. Therefore, $P\left(T^{\alpha}>T_{D}^{\alpha} \mid Z_{3}\right)=1$.

The total probability that in the case shown in Fig. 3, a real number $\mathrm{t}$ chosen from the interval $T^{\alpha}$ will be greater than the real number td chosen from the interval $T_{D}^{\alpha}$ is:

$P\left(T^{\alpha}>T_{D}^{\alpha}\right)=\sum_{q} P\left(Z_{q}\right) P\left(T^{\alpha}>T_{D}^{\alpha} \mid Z_{q}\right)=0,5 \frac{t_{d_{U}}^{\alpha}-t_{d_{L}}^{\alpha}}{t_{U}^{\alpha}-t_{L}^{\alpha}}+\frac{t_{U}^{\alpha}-t_{d_{U}}^{\alpha}}{t_{U}^{\alpha}-t_{L}^{\alpha}}$

In a similar way, one can calculate the probability $P\left(T^{\alpha}>T_{D}^{\alpha}\right)$ for other cases than the one shown in Fig. 3 . By aggregating the probability $P\left(T^{\alpha}>T_{D}^{\alpha}\right)$, calculated for the finite number of $\alpha$-cuts of fuzzy numbers $\tilde{T}$ and $\tilde{T}_{D}$, one can obtain:

$P\left(\tilde{T}>\tilde{T}_{\mathrm{D}}\right)=\frac{\sum_{i} \alpha_{i} P\left(T^{\alpha_{i}}>T_{D}^{\alpha_{i}}\right)}{\sum_{i} \alpha_{i}}$

where $i$ is the index of the given $\alpha$-cut.

\section{Results and discussion}

\section{Numerical example}

The scope of an exemplary construction project covers the finishing works in 6 buildings. Duration of activities is modeled in the form of trapezoidal fuzzy numbers. The network model is shown in Fig. 4. Fuzzy durations of works (in working days) and the planned earliest dates of the execution of

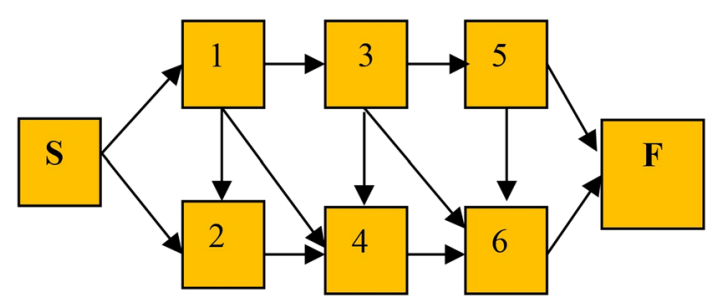

Fig. 4 Network model of exemplary construction project works calculated on the base of Eqs. (7) and (8) are given in Table 1.

Suppose that the project due time is 25 working days from the date of commencement of works. The delay results in payment of liquidated damages by the contractor for the customer, but if the construction makespan will be greater than 30 working days, the client will withdraw from the contract due to the fault of the contractor. This constraint for the construction project makespan is modeled by the fuzzy number $\tilde{T}_{\mathrm{D}}=(25,25,25,30)$. The fuzzy schedule with early time for each activity and time constraints is presented in Fig. 5.

To determine the probability $P\left(\tilde{T} \leq \tilde{T}_{D}\right)$, one can introduce $\alpha$-cuts of numbers $\tilde{T}$ and $\tilde{T}_{D}$ on the levels varying from $\alpha=0,1$ to $\alpha=1,0$, with the grading for example at 0,1 . For individual $\alpha$-cuts, one can determine the probability $P\left(T^{\alpha_{i}}>T_{D}^{\alpha_{i}}\right)$ using Eq. (14). Then, aggregate the results using Eq. (15). Finally, using the Eq. (11), one can determine the probability of compliance of the planned project makespan with the fuzzy time constraint. In this example, $P\left(\tilde{T} \leq \tilde{T}_{\mathrm{D}}\right)=0,75$.

The correctness of the result can be checked by simulation. For this purpose, one can generate random $\alpha$-cuts of fuzzy numbers $\tilde{T}_{j}$, modeling durations of individual works. Then for every generated $\alpha$-cut, determine the lower limit $t_{j_{L}}^{\alpha}$ and the upper limit $t_{j_{U}}^{\alpha}$ of an interval $T_{j}^{\alpha}$. Also, one can generate random values of coefficients $\beta_{j}$, characterizing the risk attitude of a planner. On this basis, it is possible to determine the duration of each activity $t_{j}$ :

$t_{j}=\beta_{j} t_{j_{L}}^{\alpha}+\left(1-\beta_{j}\right) t_{j_{U}}^{\alpha}$.

Then, for each simulation, one should determine the earliest start and finish dates for the individual activities and for the whole project (project start date was set to zero). In a similar manner, one can determine the value of the time constraint in each simulation. After the prescribed number of simulations, one should determine the relative frequency of cases in which the duration of the project does not exceed the project time limit, in

Table 1 Fuzzy durations of works and the planned earliest dates of the execution of works

\begin{tabular}{llll}
\hline Activity & Fuzzy duration & Earliest start & Earliest finish \\
\hline Start & $(0,0,0,0)$ & $(0,0,0,0)$ & $(0,0,0,0)$ \\
1 & $(2,4,6,8)$ & $(0,0,0,0)$ & $(2,4,6,8)$ \\
2 & $(3,4,5,6)$ & $(2,4,6,8)$ & $(5,8,11,14)$ \\
3 & $(4,7,8,11)$ & $(2,4,6,8)$ & $(6,11,14,19)$ \\
4 & $(6,7,8,9)$ & $(6,11,14,19)$ & $(12,18,22,28)$ \\
5 & $(4,5,7,8)$ & $(6,11,14,19)$ & $(10,16,21,27)$ \\
6 & $(2,3,4,5)$ & $(12,18,22,28)$ & $(14,21,26,33)$ \\
Finish & $(0,0,0,0)$ & $(14,21,26,33)$ & $(14,21,26,33)$ \\
\hline
\end{tabular}


Fig. 5 The fuzzy project schedule with time constraints

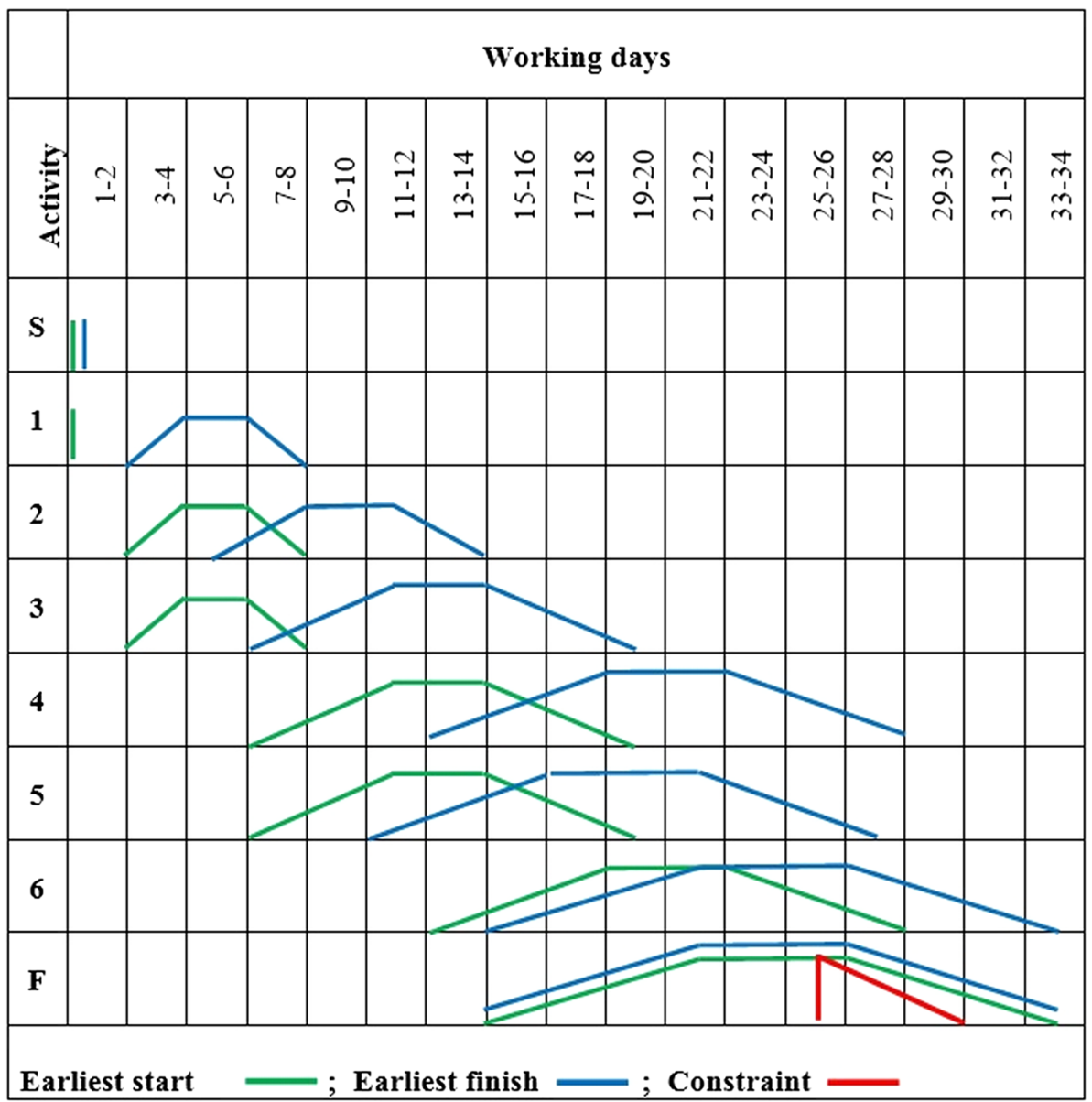

Table 2 The probability $P\left(T^{\alpha_{i}}>T_{D}^{\alpha_{i}}\right)$

\begin{tabular}{ll}
\hline$\alpha_{i}$ & $P\left(T^{\alpha_{i}}>T_{\mathrm{D}}^{\alpha_{i}}\right)$ \\
\hline 0,1 & 0,286889 \\
0,2 & 0,283904 \\
0,3 & 0,280355 \\
0,4 & 0,276063 \\
0,5 & 0,270771 \\
0,6 & 0,26408 \\
0,7 & 0,255353 \\
0,8 & 0,243494 \\
0,9 & 0,226445 \\
1,0 & 0,19985 \\
\hline
\end{tabular}

accordance with customer preferences. This leads to the determination of the probability $P\left(\tilde{T} \leq \tilde{T}_{D}\right)$. In this example, after 100,000 simulations, $P\left(\tilde{T} \leq \tilde{T}_{D}\right)=0,75$. The probability $P\left(T^{\alpha_{i}}>T_{D}^{\alpha_{i}}\right)$, determined analytically for the chosen $\alpha$-cuts of fuzzy numbers $\tilde{T}=(14,21,26,33)$ and $\tilde{T}_{D}=(25,25,25,30)$, is given in Table 2.

The results of simulations for the determination of the probability $P\left(\tilde{T} \leq \tilde{T}_{D}\right)$ are shown in Fig. 6 .
The results show the compliance of the assessment using the presented method and the simulation method.

\section{Conclusion}

The sound literature sources recommend to use the elements of fuzzy sets theory for assessing the compliance of the planned project makespan with the fuzzy time constraint. In some cases, such an evaluation may not lead to indicating the timing option, which provides a higher level to meet the time constraints of construction in accordance with client preferences. As a tool to assist decision making in such cases, this article presents a method combining elements of fuzzy set theory and probability theory. In contrast to the method of assessing the risk of schedule with the measures of necessity and possibility, the presented method enables the direct determination of the probability of meeting the fuzzy time constraint. The numerical example shows the compliance of the assessment using the presented method and the simulation method. This confirms the correctness of the assumptions of the presented method, which allows for its use for the formulation and resolving schedule 


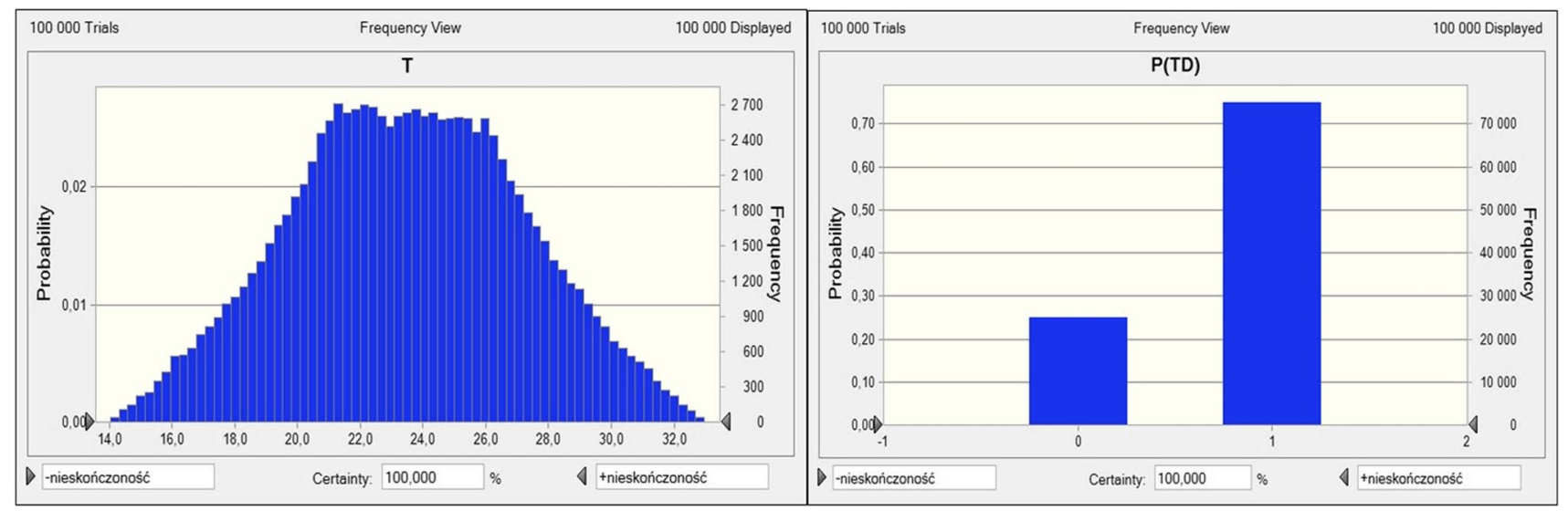

Fig. 6 Results of simulations for the probability $P\left(\tilde{T} \leq \tilde{T}_{\mathrm{D}}\right)$ determination

optimization problems in the case of imprecisely formulated schedule input data.

Acknowledgements I would like to acknowledge Warsaw University of Technology and Faculty of Civil Engineering for providing me the funds for this research (Statutory Work No. 504/02985/1088/40.000). I would also like to thank International Conference on Computational and Experimental Science and Engineering scientific committee for the possibility of research presentation.

Funding Funding was provided by ICCESEN 2017.

Open Access This article is distributed under the terms of the Creative Commons Attribution 4.0 International License (http://creativeco mmons.org/licenses/by/4.0/), which permits unrestricted use, distribution, and reproduction in any medium, provided you give appropriate credit to the original author(s) and the source, provide a link to the Creative Commons license, and indicate if changes were made.

\section{References}

Afsordegan A, Sánchez M, Agell N, Zahedi S, Cremades LV (2016) Decision making under uncertainty using a qualitative TOPSIS method for selecting sustainable energy alternatives. Int J Environ Sci Technol 13:1419-1432. https://doi.org/10.1007/s1376 2-016-0982-7

Castro-Lacouture D, Süer GA, Gonzalez-Joaqui J, Yates JK (2009) Construction project scheduling with time, cost, and material restrictions using fuzzy mathematical models and critical path method. J Constr Eng and Manag 135(10):1096-1104. https://doi. org/10.1061/ASCE0733-93642009135:101096

Chanas S, Kamburowski J (1981) The use of fuzzy variables in PERT. Fuzzy Sets Syst 5(1):1-19. https://doi.org/10.1016/01650114(81)90030-0

Chanas S, Zieliński P (2001) Critical path analysis in the network with fuzzy activity times. Fuzzy Sets Syst 122(2):195-204. https://doi. org/10.1016/S0165-0114(00)00076-2

Chanas S, Zieliński P (2002) The computational complexity of the criticality problems in a network with interval activity times. Eur J Oper Res 136(3):541-550. https://doi.org/10.1016/S0377 $-2217(01) 00048-0$
Chandra C, Kumar S (2014) Metric distance ranking technique for fuzzy critical path analysis. J Appl Sci Environ Manag 18:583-589

Dubois D, Prade H (1978) Operations on fuzzy numbers. Int J Syst Sci 9:613-626. https://doi.org/10.1080/00207727808941724

Dubois D, Prade H (1992) When upper probabilities are possibility measures. Fuzzy Sets Syst 49(1):65-74. https://doi. org/10.1016/0165-0114(92)90110-P

Dubois D, Fargier H, Fortemps P (2003) Fuzzy scheduling: modelling flexible constraints vs. coping with incomplete knowledge. Eur J Oper Res 147:231-252. https://doi.org/10.1016/S0377 -2217(02)00558-1

Elizabet S, Sujatha L (2013) Fuzzy critical path problem for project network. Int J Pure Appl Math 85(2):223-240. https://doi. org/10.12732/ijpam.v85i2.4

Głuszak M, Leśniak A (2015) Construction delays in clients opinionmultivariate statistical analysis. Procedia Eng 123:182-189. https ://doi.org/10.1016/j.proeng.2015

Hapke M, Słowiński R (1996) Fuzzy priority heuristics for project scheduling. Fuzzy Sets Syst 83:291-299. https://doi. org/10.1016/0165-0114(95)00338-X

Hapke M, Słowiński R (2000) Fuzzy set approach to multi-objective and multi-mode project scheduling under uncertainty. In: Hapke M, Słowiński R (eds) Scheduling under fuziness. Physica-Verlag, Heidelberg, pp 197-221

Herroelen W, Leus R (2005) Project scheduling under uncertainty: survey and research potential. Eur J Oper Res 165(2):289-306. https://doi.org/10.1016/j.ejor.2004.04.002

Huang W, Oh SK, Pedrycz W (2013) A fuzzy time-dependent project scheduling problem. Inf Sci. https://doi.org/10.1016/j. ins.2013.05.026

Ibadov N (2016a) Determination of the risk factors impact on the construction projects implementation using fuzzy sets theory. Acta Phys Pol A 130(1):107-111. https://doi.org/10.12693/APhys PolA.130.107

Ibadov N (2016b) Construction project selection with the use of fuzzy preference relation. AIP Conf Proc 1738:200005. https://doi. org/10.1063/1.4951977

Ibadov N (2017) Selection of construction project taking into account technological and organizational risk. Acta Phys Pol A 132(3II):974-977. https://doi.org/10.12693/aphyspola.132.974

Juszczyk M (2014) A concise review of methods of construction works duration assessment. Tech Trans 2-B:193-202 
Khalilzadeh M, Shakeri H, Gholami H, Amini L (2017) A heuristic algorithm for project scheduling with fuzzy parameters. Procedia Comput Sci 121:63-71. https://doi.org/10.1016/j.procs .2017 .11 .010

Kulejewski J (2010a) Planning of construction schedule with flexible constraints. In: Vainiunas P, Zavadskas EK (eds) 10th international conference modern building materials, structures and techniques, May 19-21, vol 1-selected papers. Vilnius Gedyminas Technical University, pp 442-445

Kulejewski J (2010b) Construction scheduling methods including fuzzy nature of the data (in Polish). Dissertation. Warsaw University of Technology. Poland

Kulejewski J (2011) Construction project scheduling with imprecisely defined constraints, The CIB international conference-MISBE 2011 "management and innovation for a sustainable built environment", June 19-23. Amsterdam, The Netherlands, MISBE 2011 Proceedings, pp 1518-1533, ISBN: 9789052693958

Li W, Liu M, Wu SZ, Xu Y (2015) An inexact optimization model associated with two robust programming approaches for water resources management. Int J Environ Sci Technol 12:2401-2414. https://doi.org/10.1007/s13762-014-0639-3

Lorterapong L, Moselhi O (1996) Project-network analysis using fuzzy sets theory. J Constr Eng and Manag ASCE 122(4):308-318. https ://doi.org/10.1061/(ASCE)0733-9364(1996)122:4(308)

Masmoudi M, Haït A (2013) Project scheduling under uncertainty using fuzzy modelling and solving techniques. Eng Appl Artif Intell 26(1):135-149. https://doi.org/10.1016/j.engap pai.2012.07.012

Plebankiewicz E, Karcińska P (2016) Creating a construction schedule specyfing fuzzy norms and the number of workers. Arch Civil Eng 62(3):149-166. https://doi.org/10.1515/ace-2015-0089

Rosłon J (2017) The multi-mode, resource-constrained project scheduling problem in construction: state of art review and research challenges. Tech Trans 5:67-74. https://doi.org/10.4467/23537 37XCT.17.070.6427

Rutkowski L (2006) Methods and techniques of artificial intelligence (in Polish). PWN, Warsaw

Shankar NR, Sireesha V, Rao BB (2010a) An analytical method for finding critical path in a fuzzy project network. Int J Contemp Math Sci 5(20):953-962

Shankar NR, Sireesha V, Rao KS, Vani N (2010b) Fuzzy critical path method based on metric distance ranking of fuzzy numbers. Int $\mathrm{J}$ Math Anal 4(20):995-1006

Slyeptsov AI, Tyshchuk TA (2003) Fuzzy temporal characteristics of operations for project management on the network model basis. Eur J Oper Res 147(2):253-265. https://doi.org/10.1016/S0377 $-2217(02) 00559-3$

Soltani A, Haji R (2007) A project scheduling method based on fuzzy theory. J Ind Syst Eng 1(1):70-80

Wang J (1999) A fuzzy set approach to activity scheduling for product development. J Oper Res Soc 50:1217-1228. https://doi. org/10.2307/3010631

Wang J (2002) A fuzzy project scheduling approach to minimize schedule risk for product development. Fuzzy Sets Syst 127:99-116. https://doi.org/10.1016/S0165-0114(01)00146-4

Wang J (2004) A fuzzy robust scheduling approach for product development projects. Eur J Oper Res 152:180-194. https://doi. org/10.1016/S0377-2217(02)00701-4

Xu J, Zheng H, Zeng Z, Wu Sh, Shen M (2012) Discrete time-costenvironment trade-off problem for large-scale construction systems with multiple modes under fuzzy uncertainty and its application to Jinping-II Hydroelectric Project. Int J Project Manage 30(8):950-966. https://doi.org/10.1016/j.ijproman.2012.01.019

Zadeh LA (1999) Fuzzy sets as a basis for a theory of possibility. Fuzzy Sets Syst 100(1):9-34. https://doi.org/10.1016/S0165 -0114(99)80004-9 